\title{
Development of Ports Carbon Emission Estimation System
}

\author{
Hyung Rim Choi ${ }^{1}$, Sung Il Byeon ${ }^{2}$ and Chang Hyun Park ${ }^{3}$ \\ ${ }^{1,2,3}$ Department of Management Information Systems, Dong-A University, Korea \\ $\left\{{ }^{1}\right.$ hrchoi, ${ }^{2}$ skpr12\}@dau.ac.kr \\ 3archehyun@naver.com
}

\begin{abstract}
In line with the ever-tightening environmental regulations, countries all over the world are exerting efforts for the establishment of eco-friendly policies. Also, in the area of maritime and ports, the greening of the maritime and ports logistics area is emerging as an urgent task because of the serious level of pollution and increased carbon emissions in port regions. In order to respond to climate change within this age of "low-carbon green growth," the construction of eco-friendly green ports becomes increasingly important. As such, many countries in the world are making various efforts to establish policy directions for the construction of eco-friendly ports. To reduce greenhouse gas, a systematic and reliable estimation system is very important. Accordingly, this research developed and suggested a system that can estimate $\mathrm{CO} 2$ emission from port facilities for the construction of green ports and the reduction of carbon emissions. It is expected that this system will be used as a basic data system in the policies for climate change response and greenhouse gas reduction, thus providing a more efficient management of carbon through a dimensional analysis of its emission sources.
\end{abstract}

Keywords: Green Port, carbon, Estimation System

\section{Introduction}

According to the national greenhouse gas inventory report, the greenhouse gas emission of Korea in 2012 was 688 million tons, ranking 6th in the world and the 5th among Organisation for Economic Co-operation and Development (OECD) countries [1, 5].

This shows a 9\% increase from 2009, which has placed Korea in the 4th place behind the United States, Japan, and Germany among OECD countries. In particular, the rate of increase in CO2 emission from Korea's fuel burnup in 2012 increased by $152 \%$ from 1990, the global standard year for greenhouse gas reduction, which places Korea in the first place among OECD countries. Currently, Korea does not have an obligation to reduce greenhouse gas. However, from 2012, there is a high possibility for Korea to be included in the list of countries obligated to conduct reduction. Thus, it becomes necessary for us to make efforts in the construction of a green-growth base for greenhouse gas reduction. In Korean ports, air pollutants emitted from concentrated cargo-handling equipment, vessels, and trucks are estimated to exist in a considerably high level. In Incheon Port, 52,974 tons of $\mathrm{CO} 2$ are annually emitted, which accounts for the largest percentage $(91.2 \%)$ of major air pollutants. It is an urgent task for Korea to establish a plan for the construction of low-carbon ports, including the Busan Port, which ranked 5th in the world in processing the container cargo [2]. More importantly, there is a need to systematically proceed with the plan. Accordingly, the Ministry of Land, Transport and Maritime Affairs has established - and is now carrying out - the Green Port policy for the construction of low-carbon, eco-friendly, and green ports in the overall areas of port development and operation in order to respond to the climate change and consistently promote green growth [1, 3]. However, despite the efforts for the productivity 
improvement of existing terminals and the introduction of eco-friendly technologies, such efforts are not connected to fruitful results because of the structural problems of existing terminals such as basic equipment and devices.

At this point, when the introduction of a new ports logistics technology is necessary because of the ever-increasing cargoes, emergence of super-large vessels, and increase of the demand for greenhouse gas reduction, countries from all over the world are competitively making investments in the development of low-carbon and high-efficiency terminals to predominate the markets. In particular, the number of plans for additional container terminal development, in consideration of the trend of increase in container cargoes, is recently increasing all over the world [4]. For the efforts of the green port construction to bear specific fruits through productivity improvement and the introduction of eco-friendly technologies, it is considered very important to accurately identify the actual state of greenhouse gas emission and to establish the reduction goal accordingly [5].

However, in current ports, the management of greenhouse gas is insufficiently conducted because of the lack of a systematic and reliable estimation system for greenhouse gas reduction. The existing systems have a structure where users have to directly enter the total volume of carbon emission into the system for calculation, which makes it virtually impossible for them to estimate carbon emission without accurate information on carbon emission. Moreover, existing systems only provide users with carbon emission information in basic table form or as numerical figures. This makes it difficult for users to use the information for a systematic management of carbon emission.

Accordingly, this research studied the method of estimating $\mathrm{CO} 2$ emission in ports and designed a system that can estimate the $\mathrm{CO} 2$ emission. In particular, to support the decision-making process for the construction of low-carbon terminals, this research designed a system that can estimate the $\mathrm{CO} 2$ emission that occurs in accordance with the port equipment operation plan, which is connected with the port operation simulation. This research also designed a user interface (UI) with the additional functions of user perception and integrated information analysis.

\section{Literature Review}

\subsection{Carbon Emission Estimation Formula}

The national greenhouse gas emission estimation method follows the standard suggested by the Intergovernmental Panel on Climate Change (IPCC) guideline of the United Nations Framework Convention on Climate Change (UNFCC). For the estimation of greenhouse gas emission in ports, this research uses the greenhouse gas emission measurement method in accordance with the energy consumption and applies the IPCC estimation method that is suitable for the international standard. Greenhouse gases include six kinds $-\mathrm{CO}_{2}, \mathrm{CH}_{4}, \mathrm{~N}_{2} \mathrm{O}, \mathrm{HFCS}$, PFCS, and $\mathrm{SF}_{6}$ - but this research only estimated $\mathrm{CO}_{2}$, which had the highest quantity and a high level of interest from the people. Moreover, this research referred to the $\mathrm{CO}_{2}$ emission estimation formula suggested in the researches of Hwan Seong Kim and Min Ji Choi (2008) [9].

The estimation target can be classified into port equipment and outside trucks in accordance with the $\mathrm{CO}_{2}$ emission source. Also, it can be classified into pier work, yard work, and transportation work in accordance with the type of work. For pier work, the container crane is mainly used, while for yard work, T/C and Y/T are used. For transportation work, Y/T is mainly used. In this research, $\mathrm{CO}_{2}$ emission, in accordance with fuel and electricity consumption, is estimated without consideration of the characteristics of each equipment type. As the vessels are regarded as fixed emission source in ports during the operation simulation, they were excluded from the estimation of $\mathrm{CO}_{2}$ emission in this research. 


$$
\mathrm{CO}_{2 \text { load andurload }}=\sum_{i}^{4} E_{i} C_{i}
$$

Here, $i$ refers to the type of fuel, while $C_{i}$ and $E_{i}$ mean the fuel consumption and the $\mathrm{CO}_{2}$ emission coefficient in accordance with the fuel type, respectively.

The $\mathrm{CO}_{2}$ emission of the container trucks and general trucks, after they enter the port gate and go out of the gate again, is calculated using their fuel consumption per hour. The loading and non-loading (stop) fuel consumption of each type of truck were used for calculation, and the mean value of their transportation speed in the port was also calculated.

$$
\mathrm{CO}_{2 \text { truck(moring) }}=\sum_{\mathrm{i}=1}^{3}\left\{\mathrm{~T}_{\Xi} \times \mathrm{F}_{\mathrm{Ri}} \times \mathrm{T}_{\mathrm{i}} \times \mathrm{E}_{1}\right\}_{\text {(2) }}
$$

Here, $T_{n i}, F_{R i}, T_{i}, E_{1}$ indicates the number of trucks, fuel consumption during loading and transportation time, as well as the diesel $\mathrm{CO}_{2}$ emission coefficient, respectively.

$$
\mathrm{CO}_{2 \text { truck(atoo })}=\sum_{\mathrm{i}=1}^{3}\left\{\mathrm{~T}_{\Xi} \times \mathrm{F}_{\mathrm{Wi}} \times\left(\mathrm{T}_{\mathrm{W}}-\mathrm{T}_{\mathrm{i}}\right) \times \mathrm{E}_{1}\right\}
$$

Here, $F_{W i}, T_{w}$ indicates fuel consumption during non-loading and staying time in ports, respectively. However, $i$ indicates three types of truck such as a container truck, general truck, and another kind of truck. Also, in the case of more than two hours of staying time in ports, the trucks are regarded to have stopped the engine without idling.

\subsection{Current State of the Carbon Emission Estimation System}

In the preceding domestic studies on the method of estimating greenhouse gas emission in ports, Hwan Seong Kim, et al., (2008) classified carbon emission from ports into diesel, heavy oil, LPG, steam, and electricity. The formula was derived as divided into vessels, loading, and trucks. In addition, they carried out a survey on 42 wharfs of the Busan Port for the estimation of $\mathrm{CO} 2$ emission and derived the formula for vessels, loading, and trucks. CO2 emission during the processing of 1 TEU and 1 Ton were also calculated [9].

To identify the current status of air pollutant emission in Incheon Port facilities, Se Hyun Han, et al., (2011) prepared a list of the emission sources and reviewed the method of emission calculation. Furthermore, in 2007, with Incheon Port as the target, they calculated the emission of air pollutants, such as HC, CO, NOx, PM10, and SO2 [10].

In its "Research on the Low-carbon Port Construction Method," the Ministry of Land, Transport and Maritime Affairs calculated the CO2 emission from 28 ports and 257 wharfs across the nation. They subsequently published a report on the "Establishment of the General Plan for Green Port Construction," where the carbon-reduction goal for lowcarbon ports construction and various carbon reduction cases were introduced, and the direction of low-carbon and energy self-supporting ports logistics system construction was also suggested [3].

With regard to system development, there was also a research on the system that monitors the greenhouse gas in ports on real-time basis. To measure carbon emission from logistic equipment (container truck, cargo-handling equipment, etc.,) in the terminals, a monitoring system that can manage carbon emission on a real-time basis using IP-FRID technology was suggested. This research introduced an immediate and accurate carbon emission monitoring method through direct measurement, unlike the existing indirect method of carbon emission information management and measurement [11].

However, preceding researchers, as previously mentioned, have the following limitations. First, those researches have problems in the accuracy and reliability of carbon information because carbon emission is calculated based on statistical data that was only provided from the port authorities and not based on the actual movement of the various kinds of equipment and outside trucks that are operated in the ports. 
Second, the direct estimation method suggested for carbon emission measurement from the equipment cannot be used because of the current level of the domestic technology. Moreover, plenty of time and finances are required in the installation and operation of the equipment. The direct estimation method suggested by Hyung Rim Choi, et al., (2008) is the method that measures accurate emission through a direct reflection of the fuel burnup process. On the contrary, the carbon emission estimation method suggested in this research is an indirect method that theoretically estimates the emission using the types, amounts, and emission coefficients of the fuels. Currently, there are almost no proper conditions to directly measure the greenhouse gas emitted from the port equipment and outside trucks. Consequently, most countries measure carbon emission using the indirect method.

\section{Carbon Emission Estimation System}

\subsection{Designing of Carbon Emission Estimation System}

To improve the productivity and construction of the port automation system, the terminals establish various operation plans. However, it takes plenty of time and finances to manufacture the cargo-handling equipment, attempt the operation directly on the sites, and analyze the operation result. The method of carbon emission measurement, by directly reflecting the process of fuel burnup and accurately measuring the amount of emission, is also very difficult. Thus, to efficiently conduct the measurement, a simulation method is used [8].

The port-operation simulator method is used for the purpose of productivity improvement and operation efficiency by providing a simulation function for terminal design and its optimum operation by reviewing the container terminal process. This method is also used for the simulation of a floor plan and the operation strategy of a port cargo-handling system, as well as for the prediction of terminal productivity through changes in the equipment, cargo volume, and kinds of vessels in a port cargo-handling system model.

As the outcomes of port operation simulation, the information on the kinds of port equipment, the number of equipment, the moving distance, and the kinds of fuels are generated. These information are directly associated with the estimation of carbon emission. As these information are the most important element for the prediction of carbon emission and are generated based on the actual simulated moving distance of each equipment, it can be used for carbon emission estimation. For this reason, this research uses the operation simulation modeling result for the measurement of carbon emission from the port equipment.

For efficient port operation, this research designed a system that can estimate carbon emission by storing the operation information of each equipment that were generated through port operation simulation and can provide visualized information on carbon emission that should be considered as the environmental factors.

Figure 1 shows the structure of carbon emission estimation. The whole system is largely composed of three modules and two DBs, and the modules are composed of a port information management module that can enter and manage the specifications of port equipment, the engine module that can estimate the carbon emission by collecting and analyzing the transmitted data, and the visualization module that provides carbon emission information to the users. DB is composed of a specification information DB that handles port equipment information and the DB that stores the carbon emission prediction result. 
Web-based carbon emission estimation system
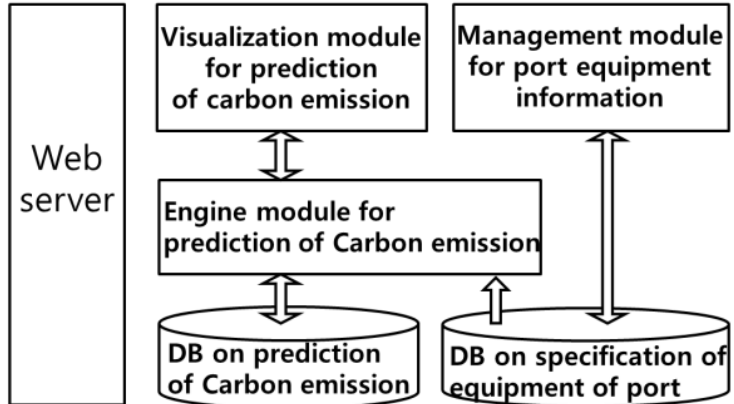

Figure 1. Example of Configuration for Web-based Carbon Emission Estimation System

The port equipment information management module is the module that can manage the specification information of the equipment operated in the ports. To accurately estimate the carbon emission, the information on the equipment operated in the ports is necessary. This system provides such functions as search, revision, deletion, and entry of the equipment specifications and also provides the user screen.

The carbon emission prediction engine module estimates the carbon emission based on the results stored in the carbon emission prediction result DB. When the operation result of each equipment generated through port operation simulation experiment is stored in the carbon emission prediction result $\mathrm{DB}$, this module delivers it to the visualization module by generating carbon emission from each equipment, location, and time zone using the estimation formula.

The visualization module generates the carbon emission delivered from the engine module in the charts or tables and shows it to the manager or user on a Web basis through visualization.

\subsection{Designing the User Interface}

The user Web interface is the practical interaction site between the user and the system, which is used by the operator and users to check the information they want. Moreover, it is one of the most important elements for most information systems. In this research, the manager interface was designed based on the UI analysis of existing carbon-emission monitoring systems. In particular, because the system developed by this research deals with the information provided in connection with the operation simulator prior to new terminal development plan, the actual system users do not have to distinguish the user UI from the manager UI. Also, this research designed the UI with a greater focus on the manager UI. The UI was made to provide a manager screen and carbon emission information. The greatest feature of this system is that it improved the accessibility so that monitoring of the carbon emission in ports can be more efficiently managed through the maximization of the user interface. The existing systems only conduct a simple calculation and provide simple figures and information on $\mathrm{CO} 2$ emission. This system, however, provides carbon emission information and carbon emission prediction results through visualized images. This can provide the users with a deep understanding of the carbon emission and help in their active decision-making for carbon emission.

As shown in Figure 2 below, the manager screen includes the function to register and manage the specification information of each equipment implemented in operation simulation. As this is the UI where the most important elements to enhance the accuracy of carbon emission estimation are entered, detailed specifications of each equipment must be entered without omission. In addition, the information on carbon emission coefficients 
necessary for estimation, such as the kinds of energy, the name of energy, unit, TOE, $\mathrm{kg}$ $\mathrm{c} / \mathrm{cj}$, and ton c/toe, should also be entered.

When registering the port equipment, the energy information used the carbon emission coefficients that were already registered, and the port equipment information was divided into port equipment and outside trucks. Here, the user interface was composed of the code, equipment type, kinds of energy, TOE, energy consumption, and carbon emission.

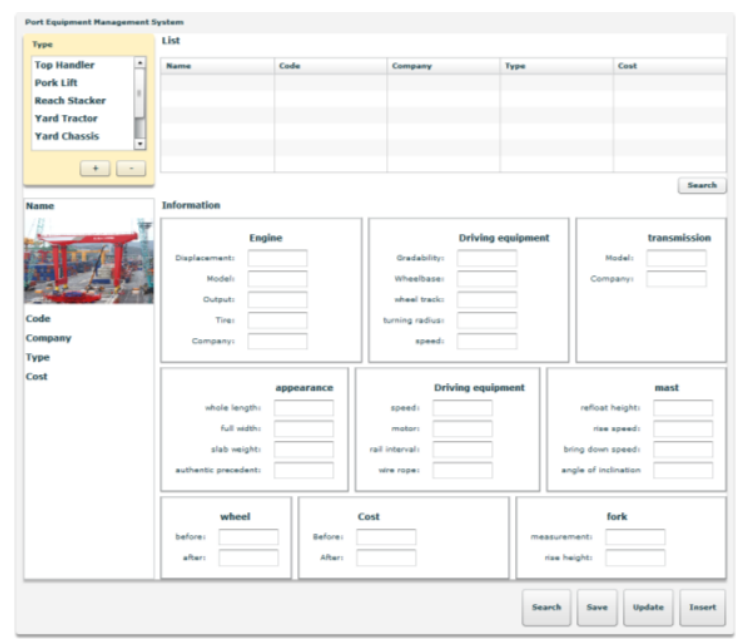

Figure 2. Port Equipment Specification Management Screen

The carbon emission information is the key information of this system. It is composed of various functions such as carbon emission list inquiry, trend of use, and various other searches. The carbon emission list inquiry function provides the list of the amount used by each carbon emission equipment. Also, it was designed to make detailed inquiry and revision possible in accordance with the request for detailed information. The trend of use indicates the trend of use in the graph for each year, month, equipment, port, and zone [Figure 4.5]. The virtual amount of use (oil, electricity, and equipment) can be entered, and the amount of carbon emission can also be simulated.

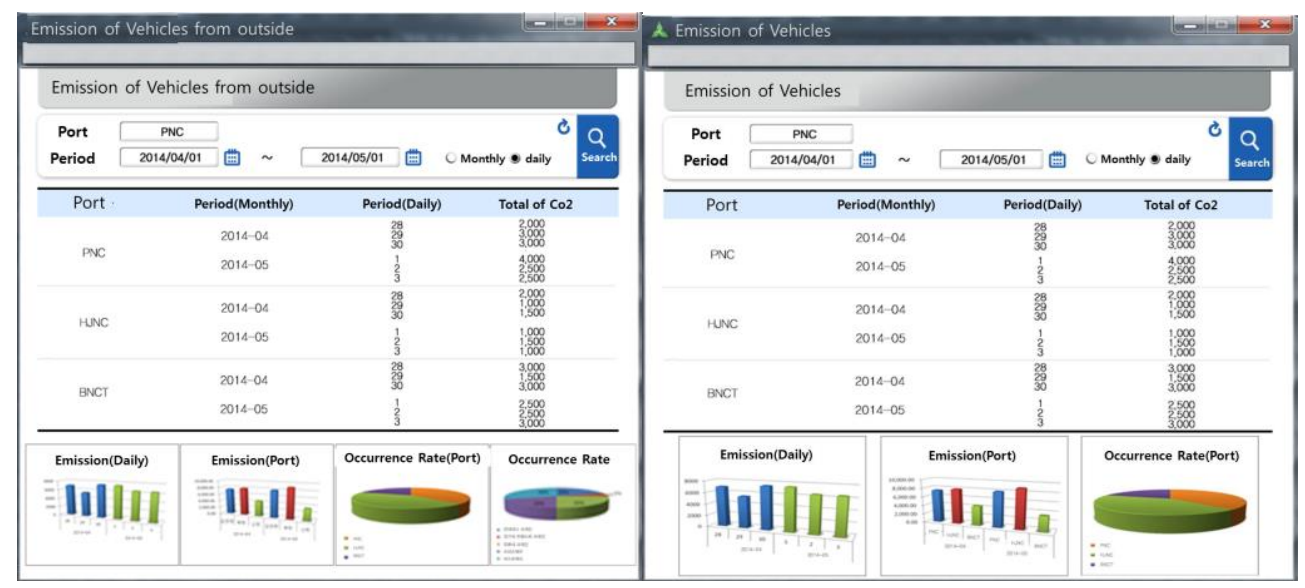

Figure 3. Carbon Emission List Inquiry UI 


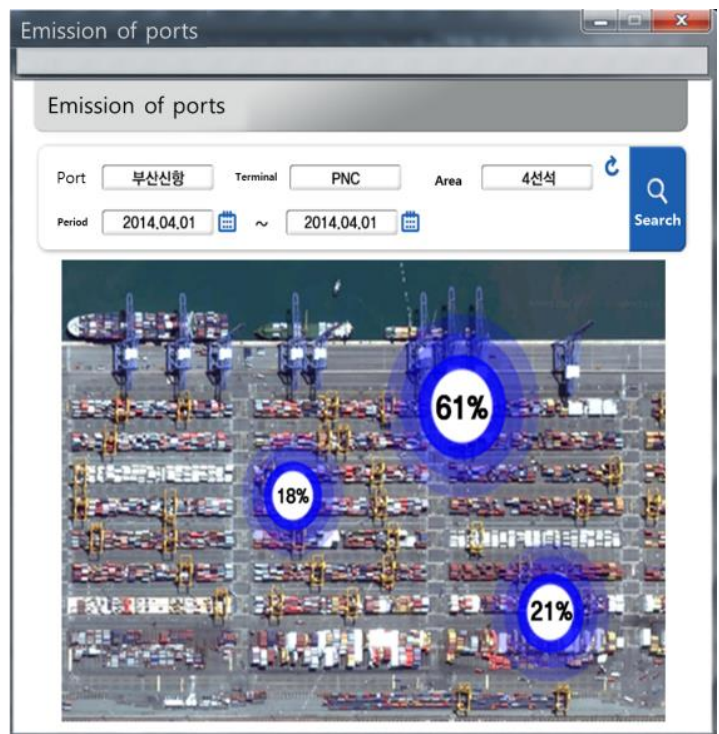

Figure 4. Carbon Emission List Inquiry UI 2

\section{Conclusion}

This research reviewed the methods of carbon emission estimation in ports and designed and suggested a system that can estimate carbon emission. In particular, to support the decision-making process for the construction of low-carbon terminals, this research designed a system that can estimate the $\mathrm{CO} 2$ emission that occurs in accordance with the port equipment operation plan in connection with the port operation simulation. This system can provide carbon emission information calculated by carbon emission coefficients after receiving the operation information of each equipment routed from the port operation simulation.

The users can enter, revise, delete, and search the necessary port specification information for the implementation of operation simulator, and they can also manage the carbon emission coefficients. The user interface was designed to make the search of the carbon emission possible as divided into each equipment, period, and work place, as well as to express the provided information in various graphs and charts through visualization. Moreover, users can simulate the amount of carbon emission by entering the amount of use for themselves. This system can help in the decision-making of the operation plan that can minimize the carbon emission in low-carbon port construction and new terminal development. Moreover, it can also be used for the estimation and monitoring of the carbon emission from each equipment and outside trucks in accordance with the operation plan of the existing terminals.

\section{ACKNOWLEDGEMENTS}

This work was supported by the Technological Development of Low-carbon Automated Container Terminals funded by the Ministry of Oceans and Fisheries, Korea

\section{References}

[1] [1] National Greenhouse Gas Inventory Report of Korea, Greenhouse Gas Inventory \& Research Center of Korea, http://www.gir.go.kr

[2] [3] D. O Cho, Environmental Impacts of International Shipping: A Case Study of the Port of Busan, OECD Report, (2010), pp. 12-17.

[3] [2] Research for GREEN Port of Korea, Ministry of Land, Infrastructure and Transport, http://english.molit.go.kr/intro.do

[4] [4] Diane Bailey, Gina Solornon, (2004), Pollution prevention at ports : Cleaning the air, Environment Impact Assessment Review 
[5] [5] G.E, Song, C.H, Han, A Study on the Strategies for the Reduction of Port Pollution, Journal of Korea Port Economic Association, (2007), Vol.23 (1), 95-113

[6] [6] Hoyle, B. S. and Smith, J., Transport and Development. In: Modern transport geography, edited by B.S .Hoyle, R.D.Knowles(London : Belhaven Press). (1992), pp.11-31

[7] [7] V. Sundramoorthy, Qi Liu, G. Cooper, N. Linge, and J. Cooper, DEHEMS: A user-driven domestic energy monitoring system, Internet of Things (IOT), (2010), p.1, p.8, Nov. 29 2010-Dec.1, Tokyo,

[8] [8] Beresford, A. K. C., De Souza, A. J. R. G. and Pettit, S. J., Strategic development of liner shipping companies and terminal operators. Ocean year book 19 (Chicago, 1L : The University of Chicago Press), (2005), pp. 732-750

[9] [9] H.S, Kim, M.J, Cho, A Study on the Calculation of C02 Emission in Port, Proceedings of the Korean Navigation and Port Research, (2008), Vol.32 (2), 137-139

[10] [10] S.H Han, J.S, Youn, W.J Kim, Y.H Seo, Y.W, Jung, Estimation of Air Pollutant Emissions from Port-Related Sources in the Port of Incheon, J. KOSAE, (2011), Vol.27, No. 4, 460 471

[11] [11] H.R Choi, B.K Park, B.H Lee, Y.S Park, C.S Lee, T.W Kwon, The Logistics Equipment Carbon Emission Monitoring System for a Green Port, Korea Society of IT Services, (2010), Vol.2010 No.01, 08-84

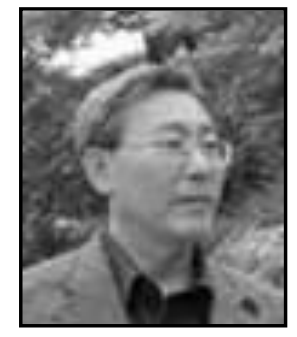

Hyung Rim Choi, is a professor of Management Information Systems at the Dong-A University in Korea. He received his BBA from Seoul National University, a M.S. and Ph.D. in management science from the Korea Advanced Institute of Science and Technology. His major research interests include AI for electronic commerce, automation of process planning and scheduling in manufacturing systems. Now he is conducting many kinds of research and R\&D activities regarding on port and logistics industry, such as development of automated container terminals, applications of information technologies including IoT(Internet of Things) to the port \& logistics industry, development of ubiquitous ports. Currently he is a director of ICC (Intelligent Container R\&D Center) performing the research tasks for the development of an intelligent container for safe cargo transportation.

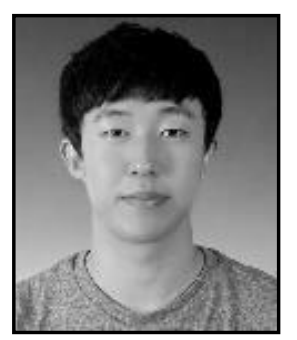

Sung Il Byeon, received his BS from Dong-A University, South Korea. He is a master degree at the Department of Management Information Systems in Dong-A University. His research interests include port and logistics systems, business information systems, and Internet of Things Systems.

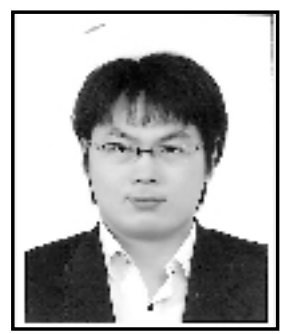

Chang Hyun Park, received his BS from Dong-A University, South Korea. He is a PhD degree from Department of Management Information Systems in Dong-A University. His research interests include port and logistics systems, business information systems, and System architecture. 